\title{
Biomass-to-biocrude on a chip via hydrothermal liquefaction of algae
}

\author{
Xiang Cheng, Matthew D. Ooms and David Sinton
}

\author{
Version Post-print/accepted manuscript \\ Citation X. Cheng, M. D. Ooms and D. Sinton. Lab Chip, 2016, 16, 256-260. \\ (published version)
}

How to cite TSpace items

\begin{abstract}
Always cite the published version, so the author(s) will receive recognition through services that track citation counts, e.g. Scopus. If you need to cite the page number of the author manuscript from TSpace because you cannot access the published version, then cite the TSpace version in addition to the published version using the permanent URI (handle) found on the record page.
\end{abstract}

This article was made openly accessible by $U$ of $T$ Faculty. Please tell us how this access benefits you. Your story matters. 


\title{
Lab on a Chip
}

\section{TECHNICAL INNOVATION}

\section{Biomass-to-biocrude on a chip via hydrothermal liquefaction of algae}

\begin{abstract}
Xiang Cheng, ${ }^{a}$ Matthew D. Ooms ${ }^{\mathrm{a}}$ and David Sinton*a
Hydrothermal liquefaction uses high temperatures and pressures to break organic compounds into smaller fractions, and is considered the most promising method to convert wet microalgae feedstock to biofuel. Although, hydrothermal liquefaction of microalgae has received much attention, the specific roles of temperature, pressure, heating rate and reaction time remain unclear. A microfluidic screening platform to precisely control and observe reaction conditions at high temperature and pressure. In-situ observation using fluorescence enables direct, real-time monitoring of this process. A strong shift in the fluorescence signature from the algal slurry at $675 \mathrm{~nm}$ (chlorophyll peak) to a post-HTL stream at $510 \mathrm{~nm}$ is observed for reaction temperatures at $260^{\circ} \mathrm{C}, 280^{\circ} \mathrm{C}, 300^{\circ} \mathrm{C}$ and $320^{\circ} \mathrm{C}(\mathrm{P}=12 \mathrm{MPa})$, and occurs over a timescale on the order of 10 min. Biocrude formation and separation from the aqueous phase into immiscible droplets is directly observed and occurs over the same timescale. The higher heating values for the sample are observed to increase over shorter timescales on the order of minutes. After only 1 minute at $300^{\circ} \mathrm{C}$, the higher heating value increases from an initial value of $21.97 \mathrm{MJ} / \mathrm{kg}$ to $33.63 \mathrm{MJ} / \mathrm{kg}$. The microfluidic platform provides unprecedented control and insight into this otherwise opaque process, with resolution that will guide the design of large scale reactors and processes.
\end{abstract}

Received 00th January 20xx, Accepted 00th January 20xx

DOI: $10.1039 / \times 0 \times x 00000 x$

www.rsc.org/ smaller fractions to produce biocrude which can be further upgraded into a variety of fuels. Optimizing the many parameters involved in HTL processing, however, remains a

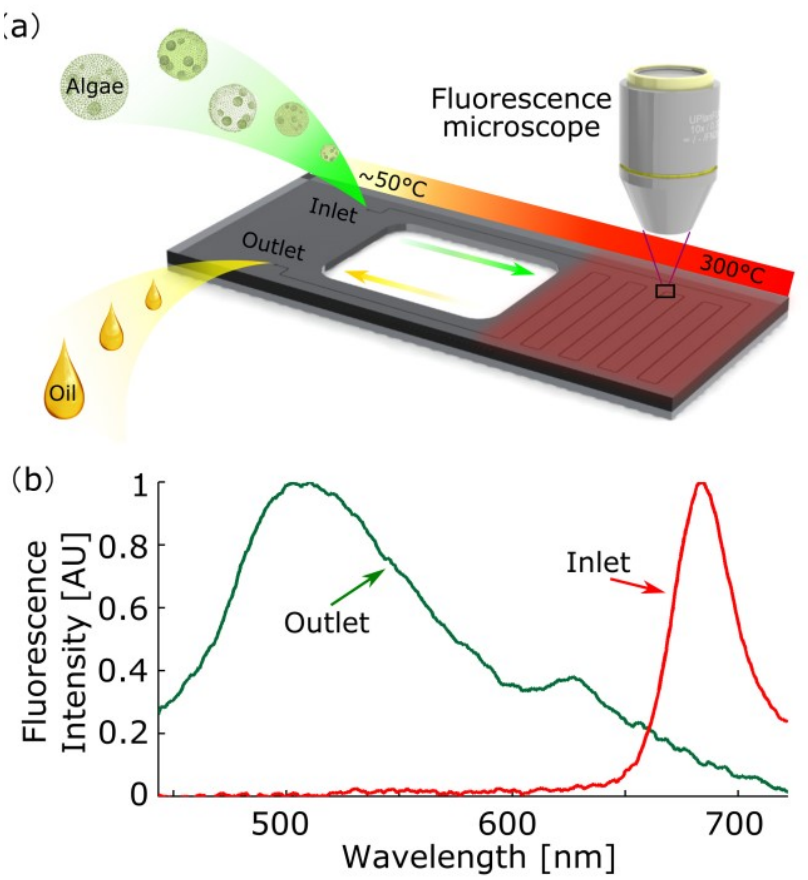

Fig. 1 a) Schematic of hydrothermal liquefaction of microalgae in the microfluidic chip with in-situ observation of biocrude production using fluorescence microscopy. b) Distinct fluorescence signatures of algae slurry at the inlet and biocrude at the outlet. 
challenge. To date, HTL experiments have been conducted in laboratory scale batch reactors using sand-baths, ovens or heating coils for temperature control. These approaches have two critical issues. First, due to the large fluid volumes and large physical size of the apparatus, substantial heating times are required, which are often ignored in the subsequent analyses. These long heating times lead to ambiguity in the reported optimal values for temperature, heating rate, and reaction time since the heating and pressurization delays blur the results. Second, in-situ monitoring of the reaction process is not possible in current reactors, precluding real-time quantification of the reaction process.

Microfluidic and lab-on-a-chip methods have recently been applied to bioenergy generation ${ }^{9-11}$, particularly with respect to microalgae. The cellular scale of microalgae makes them well suited to manipulation and analysis using microfluidic platforms. ${ }^{12,13}$ Ensuring cells receive both light and fluids is an optofluidic challenge that has been addressed, for instance, with integrated waveguides to deliver light to cultures ${ }^{14-16}$ and micro-reactor arrays integrated onto individual LCD displays for parallelized illumination and growth studies. ${ }^{17}$ These efforts have focused primarily on cultivation of microalgae, but have not addressed the downstream challenge of converting biomass into useful products.

In this work, we demonstrate a high temperature and high pressure, continuous flow, microfluidic reactor to perform controlled HTL on a glass and silicon chip (Fig. 1a). The small length-scales of the microfluidic chip enable effectively immediate heating of the algal slurry eliminating the ambiguity associated with conventional reactors. This work leverages established advantages of using high-pressure hightemperature silicon-glass microfluidic reactors ${ }^{18-23}$, for bioenergy applications. Our microfluidic chip makes possible real-time in-situ observation including fluorescence imaging and analysis as shown in Fig. 1. The fluorescence signatures from both chlorophyll in algae ${ }^{24}$ and aromatics in the produced $\mathrm{oil}^{25}$ provide direct indicators of chemical composition during the reaction.

The chip was fabricated out of glass and silicon because common chip materials such as polydimethylsiloxane (PDMS) and polymethyacrylate (PMMA) cannot support the high temperatures and pressures used in HTL and metal-based chips do not permit in-situ observation. The combination of silicon and glass allowed for (i) optical access through the glass, (ii) high thermal conductivity through the silicon, and (iii) both high pressure and temperature (over $10 \mathrm{MPa}$ and $300^{\circ} \mathrm{C}$ respectively).

The biomass injected into the chip consisted of Nannochloropsis oculata with an ash content of 5.9\% (Reed Mariculture Inc.). The as-received biomass was cleaned through centrifugation and suspended in DI water prior to use. Algal slurry at a concentration of $2 \mathrm{wt} \%$ was then injected into the chip using a high pressure pump with constant flow rate. This concentration was chosen in order to minimize clogging and fouling issues while still providing enough material to allow real-time observation of the chemical reactions on-chip and for subsequent off-chip analysis. An ultra-low flow, back

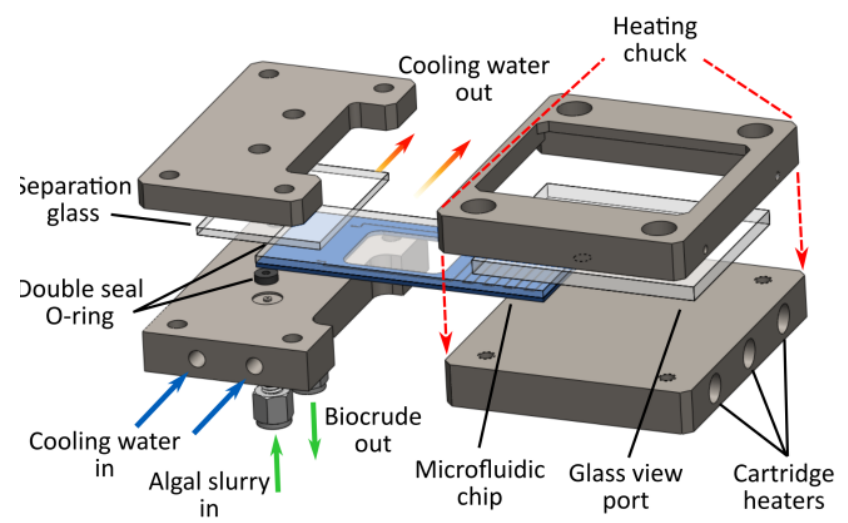

Fig. 2 Schematic representation of the assembly of the water-cooled manifold, temperature controlled heating chuck and the microfluidic chip using a separation glass and double seal O-ring to prevent cracking from hard contact.

pressure regulator (Equilibar Inc.) was used at the outlet to maintain steady flow at a constant pressure. It was essential to minimize dead volume downstream of the chip in order to collect representative samples for off-chip product analysis. Here, a separate fixed-volume sample collector loop $(300 \mu \mathrm{L})$ was incorporated into the outlet stream, immediately downstream of the chip and upstream of the backpressure regulator. The outlet line was switched using a 6-port valve with minimal dead volume (Rheodyne ${ }^{\circledR} 7030$ ). When isolated, the contents of the collector loop could be dispensed into a collection vial without depressurizing the entire chip. This enabled inline sampling directly from the output stream (see full system schematic in the ESI $\dagger$ ).

The heated region of the chip was mounted in a temperature controlled stainless steel heating chuck, as shown in Fig. 2. Precise temperature control was accomplished through a proportional-integral-derivative temperature controller with three cartridge heaters maintaining a constant temperature over the entire heating region of the chip. A thermocouple inserted in the heating chuck provided closedloop feedback and kept the temperature variation to less than $+/-1^{\circ} \mathrm{C}$ during steady state operation at a reaction temperature of $300^{\circ} \mathrm{C}$. The heating chuck was also equipped with a borosilicate glass viewing window which enabled in-situ observation of the HTL reactions that occurred in the channel. The chip manifold was maintained at a lower temperature ( $50^{\circ} \mathrm{C}$ ) to (i) prevent O-ring material failure and leakage at the ports ${ }^{21}$ and (ii) to allow rapid and controlled on-chip heating as the fluid transitioned from the cold to the hot zone (Fig. 2). Details of the manifold design can be found in supplementary information.

The square cross-section channel dimensions were $200 \mu \mathrm{m}$ $x 200 \mu \mathrm{m}$ with a total length of $1320 \mathrm{~mm}, 1250-\mathrm{mm}$ of which were located in a serpentine heating region as shown in Fig. 1a. Raw algae slurry was continuously pumped into the chip at a flow rate of $5 \mu \mathrm{L} / \mathrm{min}$ at $12 \mathrm{MPa}$. At this rate, the slurry required $10 \mathrm{~min}$ to flow through the length of the heated region. Under steady state flow, the reaction time (time spent in the heated region) at a given location along the channel could be calculated. The heating rate of $15^{\circ} \mathrm{C} / \mathrm{s}$, the fastest 
reported heating rate for HTL experiments in literature, was calculated based on the $35 \mathrm{~mm}$ length of channel between the inlet at $50^{\circ} \mathrm{C}$ and the beginning of the heating region at $300^{\circ} \mathrm{C}$.

During operation, the chip was monitored with a fluorescence microscope for changes in the fluorescence signature of the algal slurry. The sample was excited with ultraviolet light $(\lambda=375-400 \mathrm{~nm})$ and fluorescence detected through a long-pass filter $(\lambda>405 \mathrm{~nm})$ using a spectrofluorometer (ocean optics USB2000) attached to the microscope. Algae slurry was continuously pumped through the chip for 15 min to achieve steady state. By observing the fluorescence signature at different points along the channel (Fig. 3a), the progression of the HTL process as a function of time spent in the reactions chamber was quantified. Here, a

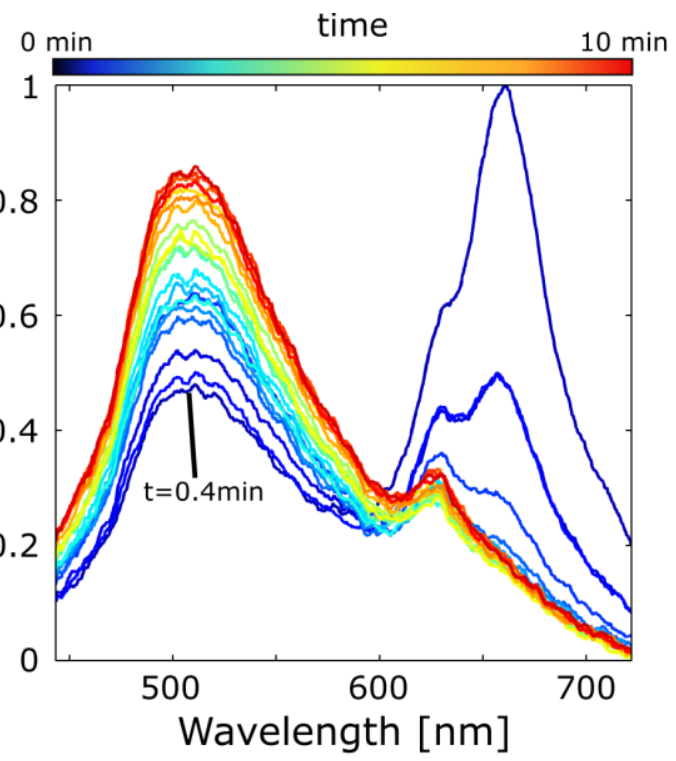

(b)

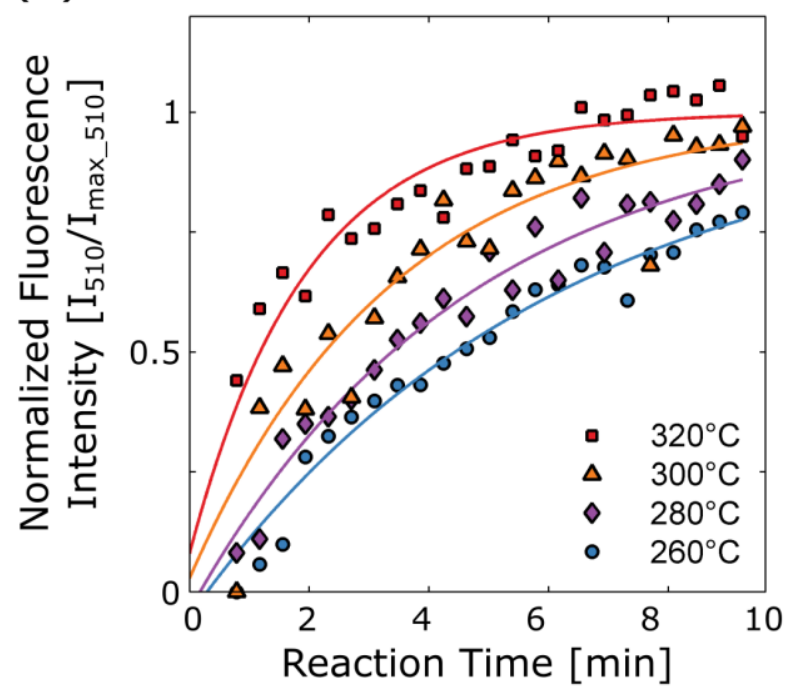

Fig. 3 a) Normalized fluorescence intensity of algae slurry observed at viewing points along the channel under $320^{\circ} \mathrm{C}$ indicating the formation of biocrude over time. b) The progression of normalized fluorescence intensity of the $510 \mathrm{~nm}$ peak at the reaction temperature of $260^{\circ} \mathrm{C}, 280^{\circ} \mathrm{C}, 300^{\circ} \mathrm{C}$ and $320^{\circ} \mathrm{C}$ indicating higher reaction temperature has higher reaction rate. Solid lines included as a guide for the eye. series of viewing points along the channel were chosen to correspond to reaction times at 0.4-min intervals, ranging from 0 to $10 \mathrm{~min}$. Near the inlet, raw algal slurry mainly showed chlorophyll fluorescence with a peak at $675 \mathrm{~nm}$ (Fig. 1b). By $1.2 \mathrm{~min}$, the chlorophyll peak had significantly dropped and an emerging peak at $510 \mathrm{~nm}$ began to rise. Over the next $2 \mathrm{~min}$, the $510 \mathrm{~nm}$ peak became dominant and continued to grow. After $10 \mathrm{~min}$, the original chlorophyll peak was no longer visible and the normalized peak intensity at $510 \mathrm{~nm}$ approached a saturation point as shown in Fig. $3 \mathrm{~b}$. The evolution of the peak at $510 \mathrm{~nm}$ indicated the formation of aromatic compounds which are a characteristic component of crude oils as well as other processed plant based oils. The progression of the fluorescence signature from one dominated by chlorophyll fluorescence to one resembling conventional crude oils tracked the progression of the HTL conversion process.

The effect of reaction temperature was investigated by performing identical experiments at $260^{\circ} \mathrm{C}, 280^{\circ} \mathrm{C}, 300^{\circ} \mathrm{C}$ and $320^{\circ} \mathrm{C}$. For each temperature, the normalized peak intensity at $510 \mathrm{~nm}$ over the course of the reaction is shown in Fig. 3b. The fluorescence signals were normalized to the projected saturation intensity based on a $1^{\text {st }}$ order exponential curve fit to the experimental data. The results in Fig. 3b clearly show that higher reaction temperatures resulted in higher reaction rates. Specifically, the characteristic times (time required for the fluorescence intensity at $510 \mathrm{~nm}$ to reach $63 \%$ of its maximum value) were: $6.0 \mathrm{~min}, 4.6 \mathrm{~min}, 3.4 \mathrm{~min}$, and $1.9 \mathrm{~min}$ for the reactions run at $260^{\circ} \mathrm{C}, 280^{\circ} \mathrm{C}, 300^{\circ} \mathrm{C}$, and $320^{\circ} \mathrm{C}$ respectively.

Produced samples were collected off-chip for analysis of their higher heating values (HHV) by isolating the reaction products in the sample collector and eluting them to small glass vials. The product at the outlet had a variety of components including water-soluble compounds and biocrude, with other smaller amounts of solid particulates and gas. To isolate the biocrude, $2 \mathrm{~mL}$ of dichloromethane was added to the recovery vial followed by vigorous shaking for several minutes, completely dissolving the biocrude into the dichloromethane. The vials were then set aside to allow complete phase separation. Once separated the dichloromethane layer was withdrawn using a glass syringe and stored in a separate vial. This extraction process was performed multiple times to ensure more than $95 \%$ of biocrude was recovered from the sample. The extracted biocrude was then heated in an oven at $40^{\circ} \mathrm{C}$ for 8 hours to remove the solvent.

The higher heating values of each sample were calculated using the modified Dulong's formula as follow:

$$
H H V(M J / k g)=0.335 C+1.423 H-0.154 O-0.145 N
$$

A carbon-hydrogen-nitrogen elemental analyser was used to measure the carbon (C), hydrogen $(\mathrm{H})$, nitrogen $(\mathrm{N})$ composition of the initial dry algae sample and the produced biocrude. The oxygen $(\mathrm{O})$ content was estimated according to: 


$$
\% \mathrm{O}=100 \%-\% \mathrm{C}-\% \mathrm{H}-\% \mathrm{~N}-\% \text { Ash }
$$

where the sulphur content is assumed to be negligible, as is

Table 1: Elemental composition and Higher Heating Value of dry algae and biocrude from $1 \mathrm{~min}, 5 \mathrm{~min}$ and $10 \mathrm{~min}$ reaction times.

\begin{tabular}{lccll}
\hline Element & Dry Algae & $\begin{array}{l}\text { Biocrude } \\
(1 \mathrm{~min} \text { RT })\end{array}$ & $\begin{array}{l}\text { Biocrude } \\
(5 \mathrm{~min} \mathrm{RT})\end{array}$ & $\begin{array}{l}\text { Biocrude } \\
(10 \mathrm{~min} \mathrm{RT})\end{array}$ \\
\hline $\mathrm{C}[\%]$ & 51.08 & 70.11 & 70.35 & 70.63 \\
$\mathrm{H}[\%]$ & 7.23 & 8.75 & 9.23 & 9.22 \\
$\mathrm{~N}[\%]$ & 8.65 & 4.46 & 6.00 & 6.56 \\
$\mathrm{O}[\%]$ & 27.14 & 10.78 & 8.52 & 7.69 \\
$\mathrm{HHV}[\mathrm{MJ} / \mathrm{kg}]$ & 21.97 & 33.63 & 34.52 & 34.65 \\
\hline
\end{tabular}

typical for microalgae. ${ }^{26,27}$ Prior to elemental analysis, the raw algae was dried in an oven at $105^{\circ} \mathrm{C}$ for an hour.

The measured HHVs of dry algae and biocrude are shown in Table 1 and correspond well with previously reported values ${ }^{28-}$ 30 using similar microalgae species and reaction conditions. As shown, the most significant increase in HHV occurred within the first few minutes of the reactions. Beyond reaction times of 1 minute, the variation of HHV was less than $5 \%$.

Combined with the fluorescence data collected, this analysis of HHV suggests that while the energy content of the biocrude approached saturation at very early times ( $1 \mathrm{~min}$ ), other

ə)

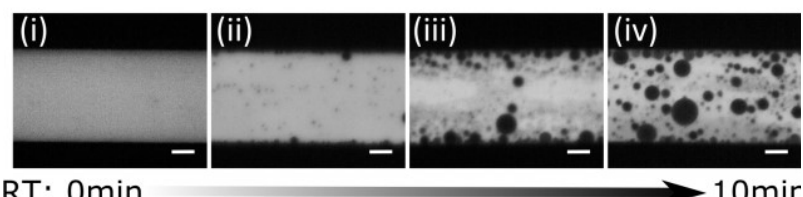

RT: Omin

$10 \mathrm{mir}$

ग)
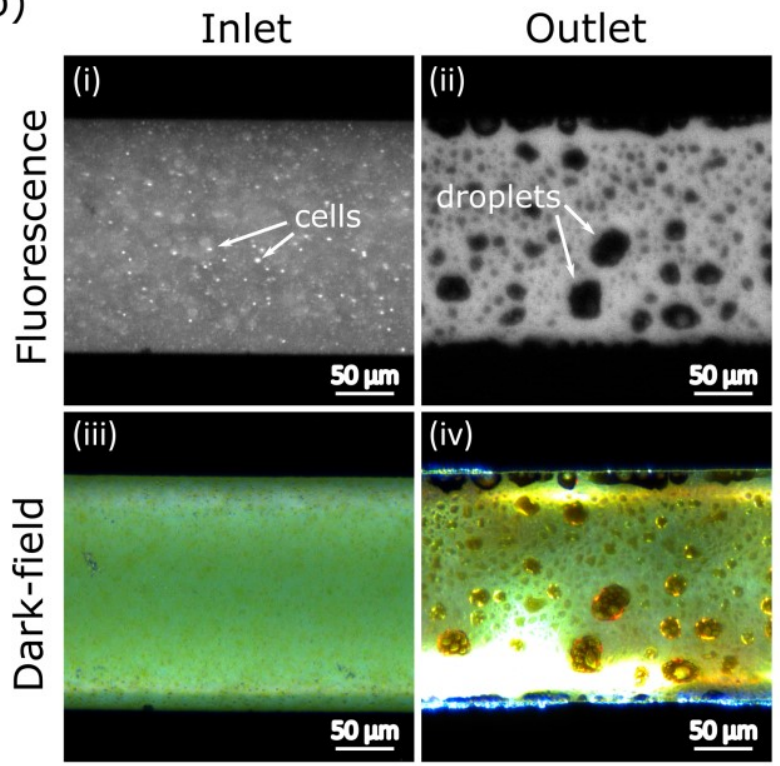

Fig. 4 a) Fluorescence images obtained at viewing points along the channel with increase in reaction time indicating the progression of biocrude formation. b) Microscopic observation of fluids at the inlet and outlet via both fluorescence and dark-field imaging. Scale bars: $50 \mu \mathrm{m}$. reactions continued to occur that were not accounted for by the HHV alone. The sharp increase in HHV during the first minute of the reaction was likely due to rupturing of the cells which made lipid extraction by dichloromethane more efficient. ${ }^{31}$ As such, the increase in HHV should be used as an indicator of mechanical disruption rather than chemical conversion which can be observed more directly with the fluorescence signal.

Direct observation of the channel during operation provided additional insight into this process. Most notably, non-fluorescent droplets were observed forming and adhering along the length of the channel and increased in size towards the outlet (Fig. 4a). These droplets are expected to be comprised of aliphatic compounds which are immiscible with water and do not fluoresce. The formation of these droplets progressed along the length of the channel which suggests a correlation between the formation of immiscible oil droplets and the parallel change in fluorescence signature resulting from the formation of aromatic compounds in the aqueous phase. Additionally, the degradation of the microalgae could be observed between the inlet where whole cells were clearly visible and the outlet where individual cells were no longer discernable (Fig. 4b).

It was also observed that a significant amount of cell debris and solid particulates (and in some cases, clogging) resulted from operating with short reaction times. Specifically, we observed that at $320^{\circ} \mathrm{C}$ when the flow rate was increased such that the maximum reaction time was only two minutes, a significant amount of solid debris remained in the effluent. In contrast, less solid debris in the output was observed for longer reaction times achieved with lower flow rates and otherwise similar conditions. This finding is likely a result of more complete disruption of the biomass during the first few minutes of the reaction (also indicated by the increase in HHV described earlier). Furthermore, clogging at the outlet was exacerbated by the rapid cooling of the effluent which promoted the separation of the oil phase from the aqueous phase, which was directly observed as an increase in the number and size of oil droplets in the cooled outlet line (Fig 4a). Lastly, the multiphase nature of the generated products, visible as channel-adhered droplets in Fig. 4, will influence to some extent the residence time, accumulation and ultimate production of different components. The HHV analysis here, however, is largely unaffected by this issue as the oil is separated from the produced fluid and based on the relative elemental composition of the biocrude. These observations, which were made possible only through the direct visualization afforded by our chip design, have implications for the optimum processing parameters of continuous flow HTL reactors. Specifically, these findings indicate optimal reaction times between 2 and 10 minutes to both maximize the conversion of biomass to biocrude, and minimize the amount of debris in the effluent to prevent fouling. Gradual cooling of outlet stream is also recommended to avoid clogging. 


\section{Conclusions}

In summary, our microfluidic reactor provides unprecedented insight and control over the high temperature and high pressure cracking of biomass via hydrothermal liquefaction. It allows for in-situ observation of hydrothermal liquefaction reactions using fluorescence microscopy and convenient and precise control of reaction temperature, pressure and reaction time in a continuous flow reactor. These advantages enable the study of high temperature and pressure cracking of biomass on a platform with a high degree of control which will allow improved understanding of the reactions taking place during hydrothermal liquefaction. The significant change of fluorescence signature between the algal slurry (peak at 675 $\mathrm{nm}$ ) and converted biomass (peak at $510 \mathrm{~nm}$ ) was observed as an indicator of the progression of hydrothermal liquefaction. Biocrude formation and separation from the aqueous phase into immiscible droplets was directly observed and occurred over timescales of $\sim 10 \mathrm{~min}$. The rapid increase of higher heating values was observed over the timescales of $\sim 1 \mathrm{~min}$ and was correlated to observations of particulate matter in the effluent which manifested as partially clogged channels. These results and the microfluidic platform on which they were collected represent the first of their kind in the field of hydrothermal liquefaction research. Lab-on-a-chip methods offer a unique toolset to probe high temperature and high pressure reaction dynamics and inform large scale reactor design.

\section{Acknowledgements}

This work was supported through a Strategic Grant from the Natural Science and Engineering Research Council of Canada, the University of Toronto Connaught Global Scholars Program in Bio-Inspired Ideas for Sustainable Energy, the University of Toronto McLean Senior Fellowship (DS), and the Vanier Canada Graduate Scholarship (MO). CHN analysis was performed by the Analest facility at the University of Toronto. Fabrication was performed at the Toronto Nanofabrication Centre and the Centre for Microfluidic Systems in Chemistry and Biology at the University of Toronto. Ongoing infrastructure support from the Canadian Foundation for Innovation is also gratefully acknowledged.

\section{Notes and references}

1 Y. Chisti, Biotechnol. Adv., 2007, 25, 294-306.

2 L. Lardon, A. Hélias, B. Sialve, J.-P. Steyer and O. Bernard, Environ. Sci. Technol., 2009, 43, 6475-6481.

3 Y. Zhu, K. O. Albrecht, D. C. Elliott, R. T. Hallen and S. B. Jones, Algal Res., 2013, 2, 455-464.

4 D. L. Sills, V. Paramita, M. J. Franke, M. C. Johnson, T. M. Akabas, C. H. Greene and J. W. Tester, Environ. Sci. Technol., 2013, 47, 687-694.

5 Y. Zhou, L. Schideman, G. Yu and Y. Zhang, Energy Environ. Sci., 2013, 6, 3765.

6 A. A. Peterson, F. Vogel, R. P. Lachance, M. Fröling, M. J. Antal, Jr. and J. W. Tester, Energy Environ. Sci., 2008, 1, 32.
7 C. C. Xu, Y. Shao, Z. Yuan, S. Cheng, S. Feng and L. Nazari, Application of Hydrothermal Reactions to Biomass Conversion, Springer Berlin Heidelberg, Berlin, Heidelberg, 2014.

8 S. Yin and Z. Tan, Appl. Energy, 2012, 92, 234-239.

9 D. Sinton, Lab Chip, 2014, 14, 3127.

10 M. Uhlen and H. Andersson Svahn, Lab Chip, 2011, 11, 3389.

11 D. Erickson, D. Sinton and D. Psaltis, Nat. Photonics, 2011, 5, 583-590.

12 N. Samsonoff, M. D. Ooms and D. Sinton, Appl. Phys. Lett., 2014, 104, 043704.

13 M. D. Ooms, Y. Jeyaram and D. Sinton, Appl. Phys. Lett., 2015, 106, 063902.

14 E. E. Jung, M. Kalontarov, D. F. R. Doud, M. D. Ooms, L. T. Angenent, D. Sinton and D. Erickson, Lab Chip, 2012, 12, 3740

15 S. S. Ahsan, A. Gumus, A. Jain, L. T. Angenent and D. Erickson, Bioresour. Technol., 2015, 192, 845-849.

16 A. Jain, N. Voulis, E. E. Jung, D. F. R. Doud, W. B. Miller, L. T. Angenent and D. Erickson, Environ. Sci. Technol., 2015, 49, 6327-6334.

17 P. J. Graham, J. Riordon and D. Sinton, Lab Chip, 2015, 15, 3116-3124.

18 K. S. Elvira, X. C. i Solvas, R. C. R. Wootton and A. J. DeMello, Nat. Chem., 2013, 5, 905-915.

19 T. Razzaq and C. O. Kappe, Chem. - An Asian J., 2010, 5, NANA.

20 V. Hessel, D. Kralisch, N. Kockmann, T. Noël and Q. Wang, ChemSusChem, 2013, 6, 746-789.

21 S. Marre, A. Adamo, S. Basak, C. Aymonier and K. F. Jensen, Ind. Eng. Chem. Res., 2010, 49, 11310-11320.

22 C. Tian, B. Li, Z. Liu, Y. Zhang and H. Lu, Renew. Sustain. Energy Rev., 2014, 38, 933-950.

23 R. Boden, S. Ogden and K. Hjort, J. Microelectromechanical Syst., 2014, 23, 452-458.

24 D. Elsey, D. Jameson, B. Raleigh and M. J. Cooney, J. Microbiol. Methods, 2007, 68, 639-642.

25 A. G. Ryder, in Reviews in Fluorescence 2005, Springer US, Boston, MA, 2005, pp. 169-198.

26 D. Xu and P. E. Savage, Algal Res., 2014, 6, 1-7.

27 S. Leow, J. R. Witter, D. R. Vardon, B. K. Sharma, J. S. Guest and T. J. Strathmann, Green Chem., 2015, 17, 3584-3599.

28 P. Biller and A. B. Ross, Bioresour. Technol., 2011, 102, 215225.

29 J. L. Faeth, P. J. Valdez and P. E. Savage, Energy \& Fuels, 2013, 27, 1391-1398.

30 H. Li, Z. Liu, Y. Zhang, B. Li, H. Lu, N. Duan, M. Liu, Z. Zhu and B. Si, Bioresour. Technol., 2014, 154, 322-329.

31 T. M. Brown, P. Duan and P. E. Savage, Energy \& Fuels, 2010, 24, 3639-3646. 